\title{
A versatile $\delta$-aminolevulinic acid (ALA)-cyclodextrin bimodal conjugate-prodrug for PDT applications with the help of intracellular chemistry
}

\author{
Chrysie Aggelidou, Theodossis A. Theodossiou ${ }^{\star}$ §, Antonio Ricardo Gonçalves, \\ Mariza Lampropoulou and Konstantina Yannakopoulou *
}

\author{
Full Research Paper \\ Address: \\ Institute of Advanced Materials, Physicochemical Processes, \\ Nanotechnology \& Microsystems, National Center for Scientific \\ Research "Demokritos", Patriarchou Gregoriou \& Neapoleos, Aghia \\ Paraskevi Attikis, 15310 Greece. Tel. +30210 6503796, Fax: +30 210 \\ 6511766 \\ Email: \\ Theodossis A. Theodossiou* - \\ Theodossis.Theodossiou@rr-research.no; \\ Konstantina Yannakopoulou* - dyanna@chem.demokritos.gr \\ * Corresponding author \\ § Current address: Department of Radiation Biology, Institute for \\ Cancer Research, The Norwegian Radium Hospital, Montebello, 0379 \\ Oslo, Norway

\section{Keywords:} \\ cyclodextrins; PDT; protoporphyrin IX; prodrug; $\delta$-aminolevulinic acid \\ Beilstein J. Org. Chem. 2014, 10, 2414-2420. \\ doi:10.3762/bjoc.10.251 \\ Received: 10 July 2014 \\ Accepted: 25 September 2014 \\ Published: 17 October 2014 \\ This article is part of the Thematic Series "Superstructures with \\ cyclodextrins: Chemistry and applications II". \\ Guest Editor: G. Wenz \\ (c) 2014 Aggelidou et al; licensee Beilstein-Institut. \\ License and terms: see end of document.
}

\footnotetext{
Abstract

Grafting of $\delta$-aminolevulinic acid (1) moieties on the narrow periphery of a $\beta$-cyclodextrin $(\beta$-CD) derivative through hydrolysable bonds was implemented, in order to generate a water-soluble, molecular/drug carrier with the capacity to undergo intracellular transformation into protoporphyrin IX (PpIX), an endogenous powerful photosensitizer for photodynamic therapy (PDT). The water-soluble derivative 2 was prepared by esterifying $\delta$-azidolevulinic acid with heptakis(6-hydroxyethylamino-6-deoxy)- $\beta$ cyclodextrin, with an average degree of substitution, DS $=3$. Delivery of water-soluble, colorless 2 to cells resulted in intense red fluorescence registered by confocal microscopy, evidently due to the engagement of the intracellular machinery towards formation of PpIX. Conjugate $\mathbf{2}$ was further complexed with a fluorescein-labeled model guest molecule which was successfully transported into the cells, thereby demonstrating the bimodal action of the derivative. The present work shows the versatility of CDs in smart applications and constitutes advancement to our previously shown PpIX- $\beta$-CD conjugation both in terms of water solubility and lack of aggregation.
} 


\section{Introduction}

Porphyrins have long been used as agents for tumor photodiagnosis (PDD) and photodynamic therapy (PDT) because of their preferential accumulation in cancerous rather than squamous tissues [1]. $\delta$-Aminolevulinic acid (1, ALA, Scheme 1) is a $\delta$-amino acid precursor in the cellular biosynthesis of heme [2]

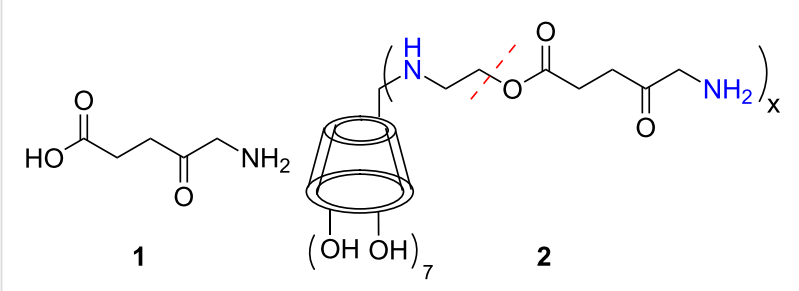

Scheme 1: The structure of $\delta$-aminolevulinic acid (1), a precursor in cellular biosynthesis of protoporphyrin IX and subsequently heme.

The penultimate step in this biosynthetic cycle is the iron chelation of protoporphyrin IX (PpIX), a porphyrin photosensitizer (PS) which was shown to be very efficient for PDT [3]. Compound 1 and its more lipophilic esters, methyl and hexyl levulinate, have been approved for clinical use as PpIX precursors against several cancers such as basal cell carcinoma, bladder cancer, actinic keratosis, etc. [4]. Compound $\mathbf{1}$ is a polar, zwitterionic compound, with inherently poor cell permeability and consequently challenging pharmaceutical formulations [5] We have recently published [6] the covalent conjugation of PpIX to $\beta$-cyclodextrin ( $\beta$-CD), a water-soluble cyclic oligosaccharide host capable of carrying hydrophobic molecules, such as drugs, in its hydrophobic cavity [7]. The cyclodextrins (CDs) are a notable family of semi-natural carbohydrate molecules approved as pharmaceutical excipients that improve the solubility and bioavailability of drugs through molecular encapsulation. We demonstrated [6] the conjugate's (PpIX-CD) bimodal action of transporting the chemotherapeutic agent tamoxifen intracellularly to engage its targets while simultaneously acting as a PS. In this sense we created a bimodal system with adequate water solubility (several $\mu \mathrm{M}$ ) able to inflict significant chemo- and phototoxicity on cancer cells. One additional benefit of tethering $\beta$-CD to PpIX, was the reduced aggregation of the conjugate in aqueous solutions. Formation of aggregates is an adverse yet typical characteristic of porphyrins that reduces their photodynamic efficiency, quenches their fluorescence and complicates their delivery [8-10]. In the system presented herein, the problems of limited aqueous solubility as well as that of aggregation are completely bypassed, as multiple copies of $\mathbf{1}$ are attached to a $\beta$-CD derivative bearing hydroxyethylamino groups in all seven positions of the narrow opening. The resulting conjugate (Scheme 1, 2) will encompass (i) the wide $\beta$-CD opening available for inclusion of a hydrophobic guest molecule for intracellular transport, (ii) positively charged secondary and primary amino groups at physiological $\mathrm{pH}$ thus able to interact with negatively charged components of the cell membranes and achieve cell penetration [11] and (iii) cleavable ester bonds expected to release 1 by the action of intracellular enzymes. Taken together, the strategy would combine prodrug photosensitizer capability with molecular/drug transport in a single versatile bimodal system.

\section{Results and Discussion}

Synthesis: The suitable $\beta$-CD derivative to be linked with ALA (1) was heptakis(6-hydroxyethylamino-6-deoxy)- $\beta$-CD (4, Scheme 2), obtained from heptakis(6-bromo-6-deoxy)- $\beta$-CD 3 and ethanolamine in high yield [12]. The choice of 4 was based on the presence of readily accessible primary terminal hydroxy groups on its narrow side, facilitating the formation of hydrolysable ester bonds with $\mathbf{1}$. The resulting conjugate 2 (Scheme 1), expected to be water soluble, comprises seven secondary and multiple primary (maximum seven) amino groups in the final form. Initial attempts to directly couple compound $\mathbf{1}$ with the terminal hydroxy groups in $\mathbf{4}$ consistently failed due to the very high propensity of $\mathbf{1}$ to reversibly lactonize or dimerize into dihydropyrazine derivatives (DHPY), which then irreversibly aromatize to pyrazines [13] thus resulting in various side products that impede purification. Protection of the $\delta$-amino group in $\mathbf{1}$ with the fluorenylmethyloxycarbonyl (Fmoc) group did not eventually lead to coupling products with 4. Furthermore, benzyloxycarbonyl (Z) protection of $\mathbf{1}$ and subsequent successful coupling reaction with $\mathbf{4}$ gave the desired Z-protected coupling product which, however, resisted removal of the $\mathrm{Z}$ protecting group under a variety of conditions [(i) $\mathrm{MeOH}, \mathrm{Pd} / \mathrm{C}, \mathrm{H}_{2}$, (ii) $\mathrm{MeOH}$, formic acid, $\mathrm{Pd} / \mathrm{C}, \mathrm{H}_{2}$, (iii) $\mathrm{MeOH}$, acetic acid, $\mathrm{Pd} / \mathrm{C}, \mathrm{H}_{2}$, (iv) $\mathrm{MeOH}$, trifluoroacetic acid, $\left.\mathrm{Pd} / \mathrm{C}, \mathrm{H}_{2}\right]$. A successful alternative was subsequently adopted comprising the linking of 4 to $\delta$-azidolevulinic acid (8) (Scheme 2). The latter, having the nucleophilicity of the $\delta$-position silenced, presented a completely straightforward precursor to $\mathbf{1}$ and proved to be amenable to coupling with $\mathbf{4}$ under various reaction conditions. Briefly [14], 8 was prepared from levulinic acid (5) through $\delta$-bromination and concomitant methyl ester formation (compound $\mathbf{6}$ ), followed by azidation to 7. Finally, enzymatic cleavage of the ester [15] resulted in liberation of the carboxylic acid functionality that is required for the coupling to the CD (Scheme 2, compound 8, Figure S1, Figure S2 in Supporting Information File 1).

The connection of $\mathbf{8}$ to $\mathbf{4}$ proceeded under standard coupling conditions (DCC, DMAP) [17] affording a water-soluble compound. The ${ }^{1} \mathrm{H}$ NMR spectrum of the product verified the presence of peaks arising both from 8 chain and 4 components, 


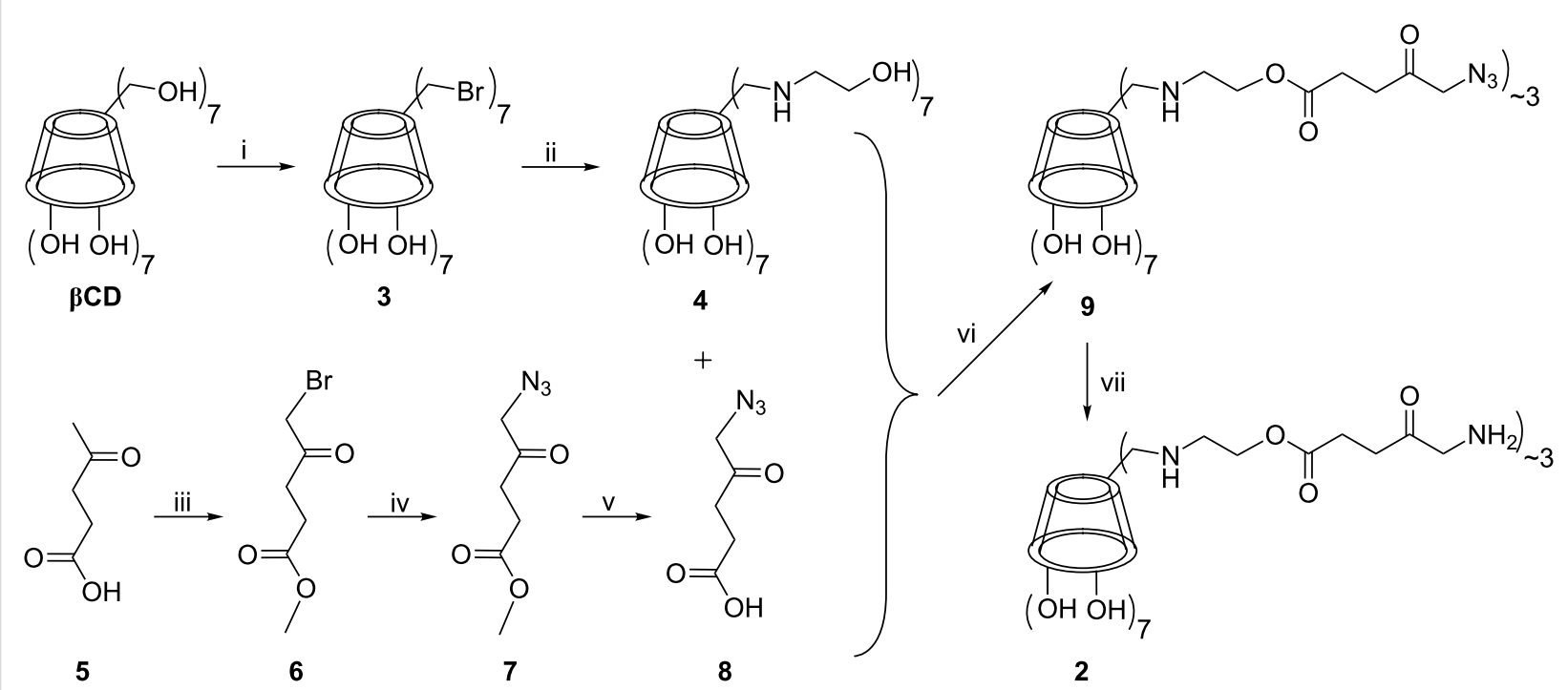

Scheme 2: Synthesis of conjugate 2 i) $\mathrm{Br}_{2}, \mathrm{Ph}_{3} \mathrm{P}$, DMF, $75-80{ }^{\circ} \mathrm{C}, 93 \%$ according to [16]; ii) 2-hydroxyethylamine, $80{ }^{\circ} \mathrm{C}, 76 \%$, according to [12]; iii) $\mathrm{Br}_{2}, \mathrm{MeOH}$, rt, $41 \%$; iv) $\mathrm{NaN}_{3}$, THF, $25-30^{\circ} \mathrm{C}, 90 \%$; v) phosphate buffer, pig liver esterase, pH 8, 25-30 ${ }^{\circ} \mathrm{C}, 82 \%$; vi) DCC, DMAP, DMF, $25-30{ }^{\circ} \mathrm{C}, 53 \%$; vii) $\mathrm{H}_{2}, \mathrm{Pd} / \mathrm{C}, 25-30{ }^{\circ} \mathrm{C}, 95 \%$.

while the relative broadness of the signals indicated incomplete/ random substitution, allowing, however, the assignment of peaks via the HSQC-edited spectrum (Supporting Information File 1, Figure S3). The ratio 8 to 4 was $\sim 3$, as indicated by integration of the respective signals and also confirmed by MALDI-TOF MS measurements ( $m / z$ 1853, Supporting Information File 1, Figure S4), whereas the IR spectrum exhibited the characteristic stretching vibrations of the azido group
(2104 $\mathrm{cm}^{-1}$, (Supporting Information File 1, Figure S5). The so obtained conjugate 9 was subsequently reduced under strongly acidic catalytic hydrogenation conditions to $\mathbf{2}$ in nearly quantitative yield.

Crucial to the spectroscopic characterization of the product was the ${ }^{13} \mathrm{C}$ NMR spectrum (Figure 1) where the ester and ketone carbonyl signals were observed along with the signals of the

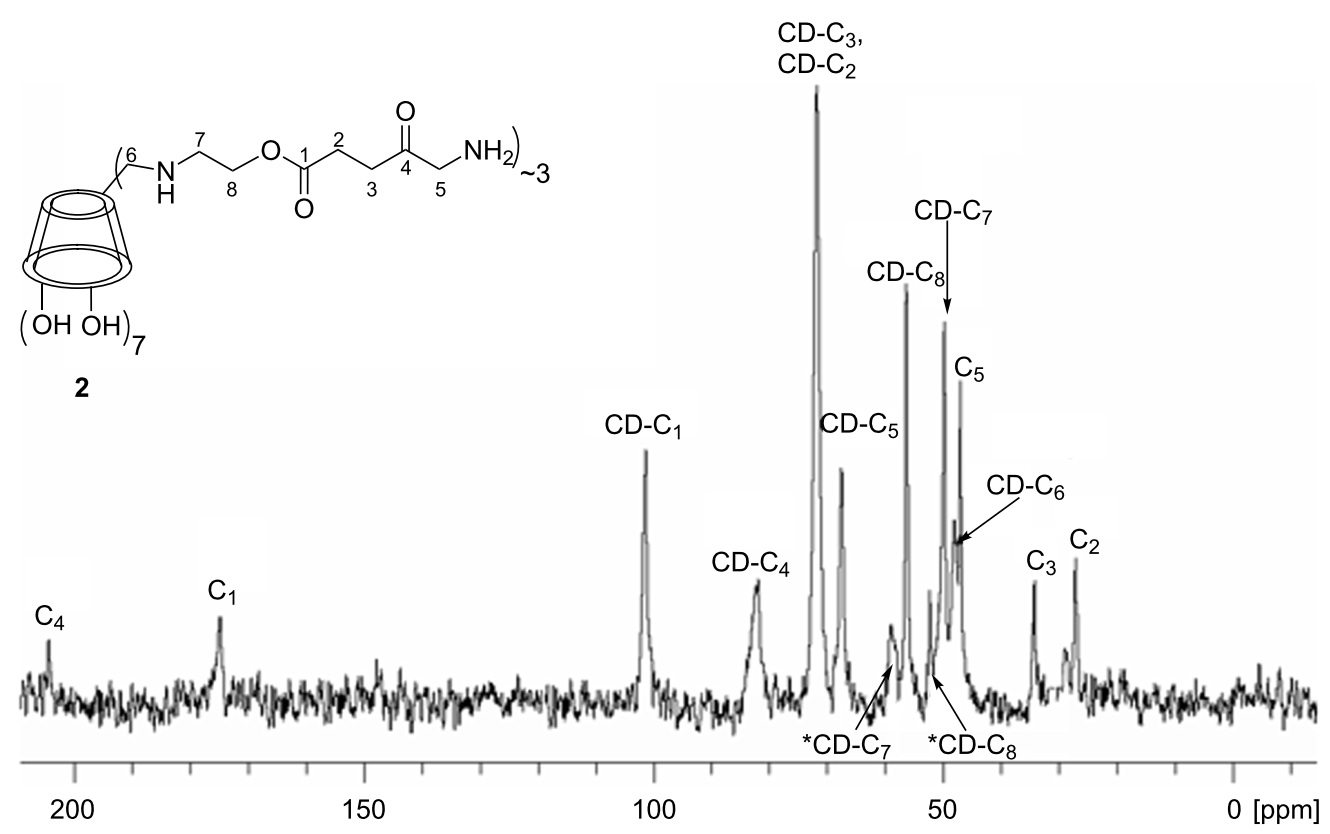

Figure $1:{ }^{13} \mathrm{C}$ NMR spectrum of $2\left(\mathrm{D}_{2} \mathrm{O}, 125 \mathrm{MHz}\right)$ with assignment of the peaks. 
$\beta$-CD moiety. Moreover, in the IR spectrum of 2 (Supporting Information File 1, Figure S5) the azido-group band disappeared, whereas prominent peaks were observed in the carbonyl region. Finally the mass spectrum confirmed the identity of the product, which maintained an average molecular weight corresponding to $\sim 3 \delta$-aminolevulinic acid moieties attached.

Cell studies with 2: The capability of the conjugate to cross cell membranes and to produce PpIX intracellularly was examined. MCF7 cells were incubated with the colorless conjugate solution for $4 \mathrm{~h}$, to allow conversion of prodrug 1 into PpIX $[5,18]$. Indeed, upon confocal microscopy imaging of the treated cells $\left(\lambda_{\mathrm{ex}}=568 \mathrm{~nm}\right)$, intense red fluorescence was observed (Figure 2), demonstrating that either (i) cell internalization was accompanied by esterolysis and release of $\mathbf{1}$ which was subsequently converted into PpIX, or (ii) one molecule of $\mathbf{2}$ with five molecules of $\mathbf{1}$ produced PpIX-(mono)CD or (iii) two molecules of $\mathbf{2}$ interacted with two molecules 1 to form PpIX(bis)CD. The first of these three scenarios is the most probable given the abundance of intracellular esterases, which would engage into activity as with the approved and marketed lipophilic esters of 1 [5], however, the other two possibilities cannot be excluded. The red fluorescence of cells incubated with 2, evidently originating from PpIX formation, was more intense in comparison with the flurorescence from cells treated with the same concentration of $\mathbf{1} \cdot \mathrm{HCl}$. Specifically, images taken from cells that were treated with either $\mathbf{1}$ or $\mathbf{2}$ under iden- tical conditions were analyzed with regard to the intensity of red color with the MATLAB software. 2D analysis and superimposition of the 1D images along the $x$-axis (Supporting Information File, Figure S7) revealed that the intensity of red fluorescence was measurably higher in both images taken from cells after treatment with 2 than in those treated with 1, irrespective of the laser intensity applied. Incubation with compound $\mathbf{1}$ and use of $100 \%$ laser intensity resulted in only small enhancement of red fluorescence.

These qualitative results show that the conjugate $\mathbf{2}$ worked much more efficiently than $\mathbf{1}$ alone, either due to the multiplicity of 1 attached and/or due to more efficient cell penetration. What can be, however, deduced from the images in Figure 2 and Figure S7 is that although the 1-treated cells were imaged at more than 3-times the laser power used for the 2-treated cells, the latter exhibited a much more intense PpIX fluorescence. This indicates that it is not the $3 \times \delta$-aminolevulinic acid molecular multiplicity of 2 that is solely responsible for the PpIX fluorescence enhancement, but either an augmented cell entry or the inhibition of ferrochelatasecatalyzed iron insertion to form non-fluorescent iron-complexed heme [19] (possibly due to the existence of PpIX-CD moieties). These suggestions as well as quantitation of subcellular processes (hydrolysis rate of $\mathbf{1}$, PpIX concentration) could only be confirmed with specific mechanistic biological studies, which lie outside the scope of the present work.
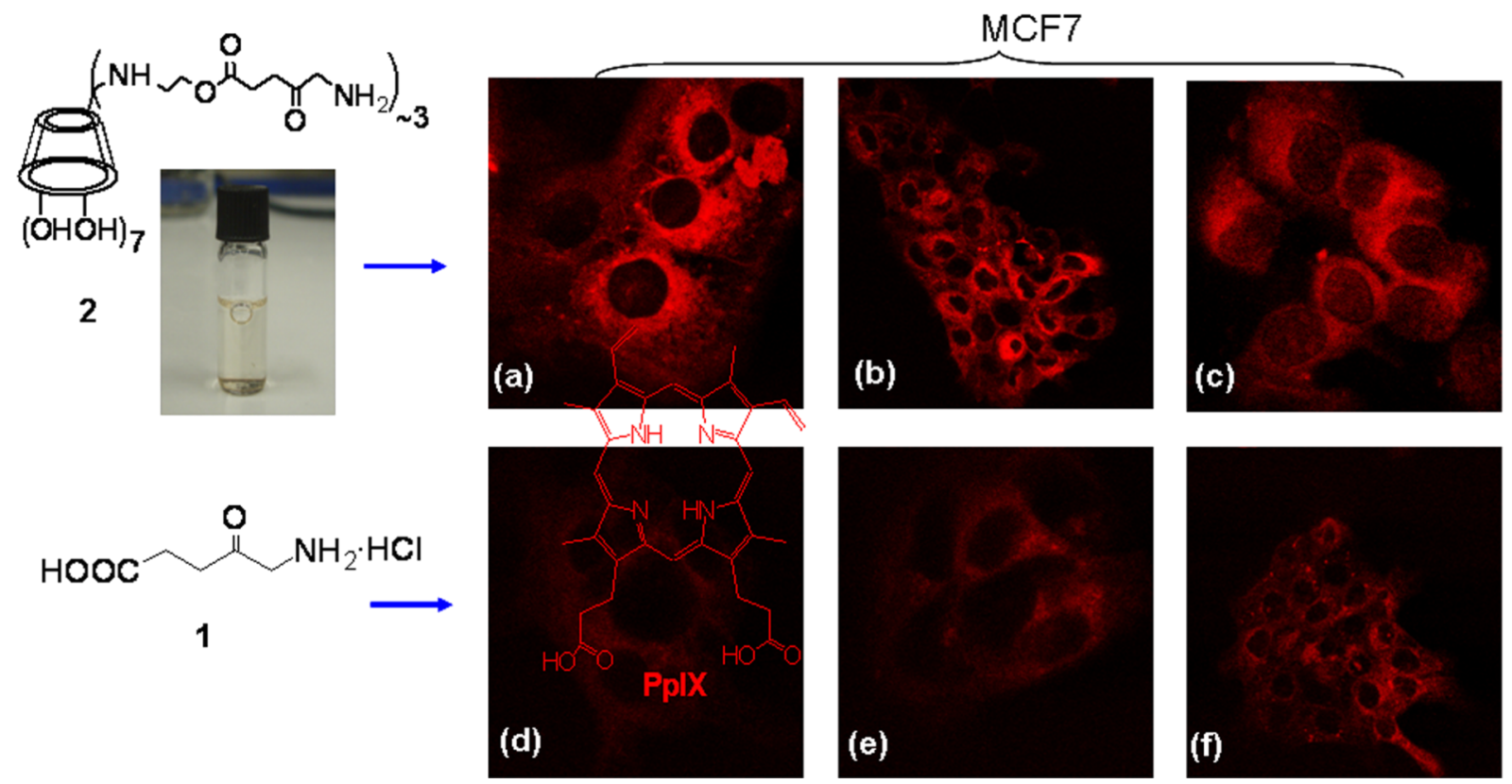

Figure 2: Representative confocal microscopy images of MCF7 cells incubated with $1 \mathrm{mM} 2$ (a, b and c), and $1 \mathrm{mM} 1$ (d, e, f), ( $\lambda_{\mathrm{ex}}=568 \mathrm{~nm}$, $\lambda_{\mathrm{em}}>585 \mathrm{~nm}$ ). The laser intensity used for the acquisition of images a, b, c was $30 \%$ of that used for images $\mathrm{d}$, e and $\mathrm{f}$. 
We further incubated MCF7 cells with 2 pre-complexed with water-insoluble fluorescein isothiocyanate-labeled 1-adamantylamine (Figure 3). The characteristic confocal microscopy images revealed red fluorescence upon excitation at $\lambda_{\mathrm{ex}}=$ $568 \mathrm{~nm}$, as well as green fluorescence upon excitation at 488 $\mathrm{nm}$. Following superimposition of the two fluorescence channels it could be concluded that PpIX production and CD guest intracellular localization, largely coincided within the cell cytoplasm (Figure 3). This indicates that possibly some of the levulinic acid ester moieties in $\mathbf{2}$ not have undergone enzymatic cleavage or hydrolysis but instead have proceeded as a conjugate through the heme biosynthesis, resulting in the biosynthesis of PpIX-CD species. This hypothesis, however, can only be confirmed by using 1-CD species, bearing no cleavable tethers to the cyclodextrin core. Moreover, is well known that $\beta$-CDs affect cells by interacting with their membrane components, namely depleting and enriching cholesterol in lipid raft and non-raft regions as well as removing and redistributing phospholipids [20]. Thus, the transport of an adamantyl-substituted guest that blocks the $\beta$-CD cavity is anticipated to alter the above host-membrane interactions. In this respect, the primary side enrichment of 1-CD with amino groups is expected to play a major role in the interaction with the anionic parts of phospholipids, rather than the $\beta-\mathrm{CD}$ cavity and its encapsulation ability of hydrophobic membrane components.

\section{Conclusion}

The present work demonstrates the synthesis and characterization of the bimodal conjugate prodrug 2 , bearing $\sim 3 \delta$-aminolevulinic acid moieties per $\beta$-CD macrocycle. The dual nature of the system was exemplified by the intracellular formation of PpIX using "intracellular chemical synthesis". At the same time 2 was able to carry inside the cytoplasm a model guest molecule. The possibility that the intracellular biosynthetic machinery may have produced some PpIX-CD species cannot be ruled out. Overall, successful $\delta$-aminolevulinic acid intracellular delivery with complete aqueous solubility, PpIX production and transport of a model guest were achieved.

\section{Experimental}

Ester of $\delta$-azidolevulinic acid with heptakis(6-hydroxyethylamino-6-deoxy)- $\beta$-cyclodextrin (9). Heptakis(6-hydroxyethylamino-6-deoxy)- $\beta$-cyclodextrin $(4,62 \mathrm{mg}, 0.043 \mathrm{mmol}$ ) was dissolved in dimethylformamide (DMF, $2 \mathrm{~mL}$ ), cooled to $0{ }^{\circ} \mathrm{C}$ and stirred for $15 \mathrm{~min}$. Then, 4-dimethylaminopyridine (DMAP, $3.7 \mathrm{mg}, 0.0302 \mathrm{mmol}$ ) and $N, N^{\prime}$-dicyclohexylcarbodiimide (DCC, $68.6 \mathrm{mg}, 0.332 \mathrm{mmol}$ ) were added, followed by $\delta$-azidolevulinic acid $(\mathbf{8}, 52.2 \mathrm{mg}, 0.332 \mathrm{mmol})$, which had previously been stirred in DMF $(1 \mathrm{~mL})$ for $6 \mathrm{~h}$ in the presence of a $\mathrm{KOH}$ pellet. The mixture was stirred at $\mathrm{rt}$ for $48 \mathrm{~h}$ under argon. Then it was centrifuged to remove insoluble side product dicyclohexylurea and the supernatant was collected and condensed to dryness. The solid residue was dissolved in a small volume of water and dialyzed from a benzoylated cellulose membrane $\left(\mathrm{MW}_{\mathrm{CO}} \sim 2000\right)$ for $24 \mathrm{~h}$. The solvent of the dialyzed solution was evaporated and the residue was lyophilized, to afford an off-white solid with degree of substitution $\sim 3,(53 \%)$. ${ }^{1} \mathrm{H}$ NMR (500 MHz, $\left.\mathrm{D}_{2} \mathrm{O}, 298 \mathrm{~K}\right) \delta 5.16$ (brs, 7H, CD-H1), 4.28 (s, 5H, H5), 3.96 (brs, 14H, CD-H3, CD-H5), 3.78 (brs, 14H, CD-H8), 3.67 (brs, 14H, CD-H2, CD-H4),
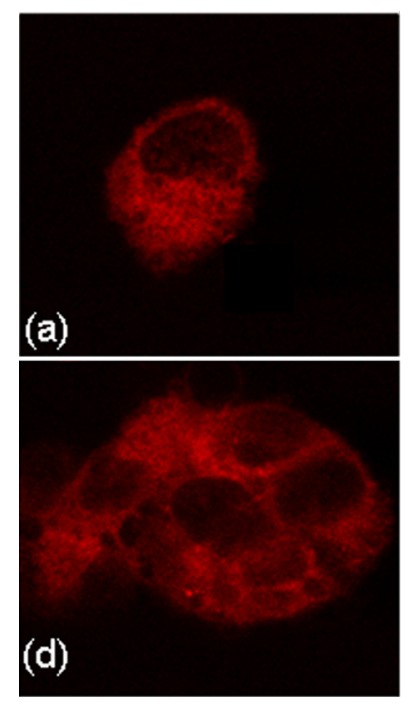
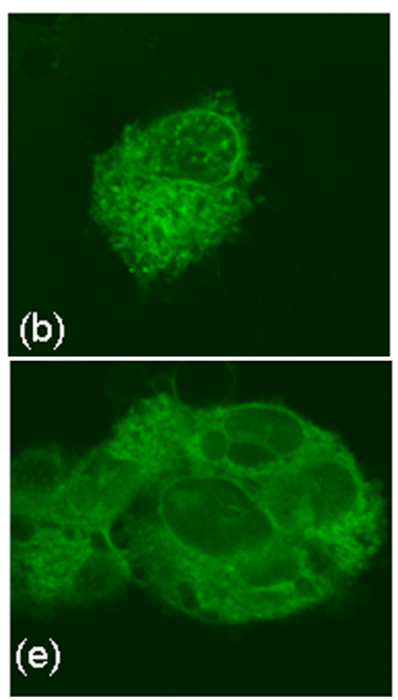
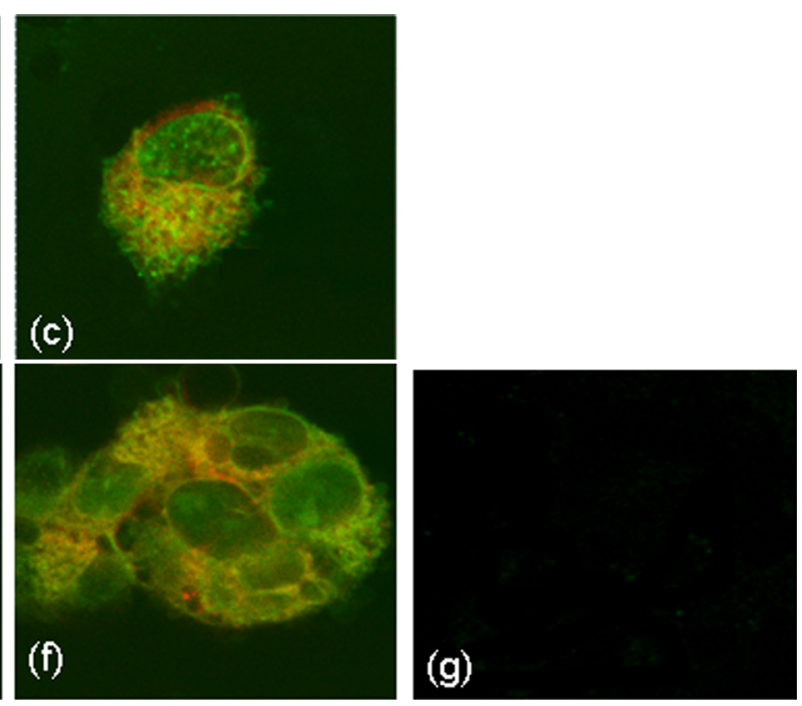

Figure 3: Representative confocal fluorescence microscopy images of MCF7 cells after incubation with a solution of 2-fluorescein isothiocyanatelabeled 1-adamantylamine (1 mM/0.2 mM) PBS: $(a, d)$ red fluorescence $\left(\lambda_{\text {ex }}=568 \mathrm{~nm}, \lambda_{\mathrm{em}}>585 \mathrm{~nm}\right) ;(\mathrm{b}, \mathrm{e})$ green fluorescence $\left(\lambda_{\mathrm{ex}}=488 \mathrm{~nm}, \lambda_{\mathrm{em}}=\right.$ $522 \mathrm{~nm}$ ); (c, f) overlay of images $\mathrm{a}, \mathrm{b}$ and of d, e: yellow color indicates guest co-localization with PpIX core; (g) blank experiment of fluorescein isothiocyanate-labeled 1-adamantylamine $\left(0.2 \mathrm{mM}\right.$ in PBS, $\left.\lambda_{\mathrm{ex}}=488 \mathrm{~nm}, \lambda_{\mathrm{em}}=522 \mathrm{~nm}\right)$. 
3.36-2.77 (m, 28H, CD-H6, CD-H6', CD-H7), 2.72 (t, $J=7.0$ $\mathrm{Hz}, 5 \mathrm{H}, \mathrm{H} 2), 2.47$ (t, $J=7.0 \mathrm{~Hz}, 5 \mathrm{H}, \mathrm{H} 3), 2.13-1.06$ (m, 1,3dicycloxylurea byproduct) $\mathrm{ppm} ;{ }^{13} \mathrm{C} \mathrm{NMR}\left(62 \mathrm{MHz}, \mathrm{CDCl}_{3}\right.$, 298 K) $\delta 207.4$ (C4), 183.1-173.4 (C1), 101.7 (br, CD-C1), 82.91 (br, CD-C4), 71.3, 72.0, 69.9 (CD-C3, CD-C5, CD-C2), 58.7 (CD-C8), 57.2 (C5), 50.29, (CD-C7), 48.70 (CD-C6,6'), 31.1 (C3), 27.0 (C2), 36.0-22.7 (1,3-dicycloxylurea byproduct) ppm; IR v: 2104.2 (vs) $\mathrm{cm}^{-1}$; MS (MALDI-TOF) $\mathrm{m} / \mathrm{z}: 1853.7$ $\left(100 \%,[\mathrm{M}+\mathrm{H}]^{+}\right)$; Exact mass calculated for $\mathrm{C}_{71} \mathrm{H}_{120} \mathrm{~N}_{16} \mathrm{O}_{41}$ (9): 1852.78 .

Ester of $\delta$-aminolevulinic acid with heptakis(6-hydroxyethylamino-6-deoxy)- $\beta$-cyclodextrin (2). To a solution of 9 $(20 \mathrm{mg}, 0.0112 \mathrm{mmol})$ in ethanol $(1 \mathrm{~mL}), \mathrm{CF}_{3} \mathrm{COOH}(250 \mu \mathrm{L})$ was added dropwise followed by addition of $\mathrm{Pd} / \mathrm{C}(7.5 \mathrm{mg}$, $0.0071 \mathrm{mmol}, 0.06$ equiv). The mixture was hydrogenated with $\mathrm{H}_{2}$ gas under stirring at $\mathrm{rt}$ for $48 \mathrm{~h}$. Subsequently the catalyst was removed by repeated centrifugation cycles and the solution was evaporated to dryness, the residue re-dissolved in water and dialyzed as above. The resulting solution was evaporated and the residue lyophilized to obtain the desired solid product (95\%). ${ }^{1} \mathrm{H}$ NMR (500 MHz, $\left.\mathrm{D}_{2} \mathrm{O}, 298 \mathrm{~K}\right) \delta 5.18$ (brs, 7H, CD-H1), 4.13 (s, 5H, H5), 3.98 (brs, 14H, CD-H3, CD-H5), 3.89 (brs, 14H, CD-H8), 3.78-3.57 (m, 14H, CD-H2, CD-H4), 3.30 (brs, 28H, CD-H6, CD-H6', CD-H7), 2.92 (t, $J=6.5 \mathrm{~Hz}$, $5 \mathrm{H}, \mathrm{H} 2), 2.73$ (t, $J=6.5 \mathrm{~Hz}, 5 \mathrm{H}, \mathrm{H} 3) \mathrm{ppm} ;{ }^{13} \mathrm{C}$ NMR $(62 \mathrm{MHz}$, $\left.\mathrm{CDCl}_{3}, 298 \mathrm{~K}\right) \delta 204.5(\mathrm{C} 4), 175.2(\mathrm{C} 1), 101.7$ (CD-C1), 82.3 (br, CD-C4), 71.8, 67.6 (CD-C3, CD-C5, CD-C2), 59.1, 56.5 (CD-C8, CD-C8), 52.5, 49.9 (CD-C7, CD-C7), 48.11 (CDC6,6'), 34.4 (C3), 27.1 (C2) ppm; MS (MALDI-TOF) $m / z$ : $1685.2\left(100 \%,[\mathrm{M}+\mathrm{Na}]^{+}\right), 1798.18\left(89 \%,\left[\mathrm{M}^{\prime}+\mathrm{Na}\right]^{+}\right)$; exact mass calculated for $\mathrm{C}_{66} \mathrm{H}_{119} \mathrm{~N}_{9} \mathrm{O}_{39}\left((\mathbf{1})_{2}-\mathrm{CD}=\mathrm{M}\right): 1661.76$ and for $\mathrm{C}_{71} \mathrm{H}_{126} \mathrm{~N}_{10} \mathrm{O}_{41}\left((\mathbf{1})_{3}-\mathrm{CD}=\mathrm{M}^{\prime}\right)$ : 1774.808 .

Complexation of fluorescein isothiocyanate-labeled 1-adamantylamine with 2 . The conjugate, 2 ( $1 \mathrm{mM}$ solution, with respect to ALA content) in phosphate buffer saline ( $\mathrm{pH}$ 7.4) was mixed with fluorescein isothiocyanate-labeled 1-adamantylamine $(0.2 \mathrm{mM})$ [21] and the dispersion was stirred for 20-30 min until a clear solution was obtained. This solution was subsequently used for cell incubation.

Cell culture: For the purposes of this study we chose the MCF7 human breast adenocarcinoma cell line. The cells were grown in RPMI 1640 without phenol red, supplemented with $10 \%$ FBS, penicillin/streptomycin at $37{ }^{\circ} \mathrm{C}$ in a $5 \% \mathrm{CO}_{2}$ and $95 \%$ humidified atmosphere

Confocal Microscopy: MCF7 cells were seeded on $22 \mathrm{~mm}$ glass coverslips in $35 \mathrm{~mm}$ dishes $\left(1 \times 10^{5}\right.$ cells per dish) $24 \mathrm{~h}$ prior to the experiments. The cells were subsequently incubated with $1 \mathrm{mM}$ of $\mathbf{1}$ or $\mathbf{2}$ or alternatively $\mathbf{2}(1 \mathrm{mM}) /$ fluorescein isothiocyanate-labeled 1-adamantylamine $(0.2 \mathrm{mM})$ for $4 \mathrm{~h}$. Afterwards the cells were washed with PBS and mounted on microscope slides for confocal fluorescence live-cell imaging performed as described previously [21]. Intracellular fluorescein isothiocyanate-labeled 1-adamantylamine was excited using the $488 \mathrm{~nm}$ line of an argon-krypton ion laser while the PpIX fluorescence was excited with the $568 \mathrm{~nm}$ line of the same laser. Fluorescein isothiocyanate-labeled 1-adamantylamine fluorescence was collected through a band-pass filter centered at $522( \pm 35) \mathrm{nm}$, while PpIX fluorescence was collected after a long-pass filter at $\geq 585 \mathrm{~nm}$. In a control experiment cells were incubated for $4 \mathrm{~h}$ with $0.2 \mathrm{mM}$ ADA-FITC in PBS.

\section{Supporting Information}

\section{Supporting Information File 1}

Full experimental procedures and detailed analytical data for the synthesis of all precursor molecules of Scheme 1; additional NMR, IR and mass spectral data.

[http://www.beilstein-journals.org/bjoc/content/ supplementary/1860-5397-10-251-S1.pdf]

\section{Acknowledgements}

Funding by the Marie Curie Initial Training Networks (FP7People-ITN-2008, Project No 237962 "CYCLON") is gratefully acknowledged. Istituto di Ricerche Chimiche e Biochimiche "G. Ronzoni" Milano, Italy, is also thanked for the MALDI-TOF measurements. We also thank A. Salapatas of our Institute for the analysis of images in Figure S7.

\section{References}

1. Dolmans, D. E. J. G. J.; Fukumura, D.; Jain, R. K. Nat. Rev. Cancer 2003, 3, 380-387. doi:10.1038/nrc1071

2. Nemeth, A. M.; Russell, C. S.; Shemin, D. J. Biol. Chem. 1957, 229, 415-422.

3. Kennedy, J. C.; Pottier, R. H. J. Photochem. Photobiol., B: Biol. 1992, 14, 275-292. doi:10.1016/1011-1344(92)85108-7

4. Gauffier, J. M.; Berg, K.; Peng, Q.; Anholt, H.; Selbo, P. K.; Ma, L.-W.; Moan, J. Cancer Res. 1997, 57, 1481-1486.

5. Vianna Lopez, R. F.; Lange, N.; Guy, R.; Lopes Badra Bentleya, M. V. Adv. Drug Delivery Rev. 2004, 56, 77-94. doi:10.1016/j.addr.2003.09.002

6. Aggelidou, C.; Theodossiou, T. A.; Yannakopoulou, K. Photochem. Photobiol. 2013, 89, 1011-1019. doi:10.1111/php.12127

7. Szejtli, J. Cyclodextrin Technology; Kluwer Academic: Dordrecht, 1988. doi:10.1007/978-94-015-7797-7

8. Hunter, C. A.; Sanders, J. K. M. J. Am. Chem. Soc. 1990, 112, 5525-5534. doi:10.1021/ja00170a016

9. Siggel, U.; Bindig, U.; Endisch, C.; Komatsu, T.; Tsuchida, E.; Voigt, J.; Fuhrhop, J.-H. Ber. Bunsen-Ges. Phys. Chem. 1996, 100, 2070-2075. doi:10.1002/bbpc.19961001225 
10. Kano, K.; Fukuda, K.; Wakami, H.; Nishiyabu, R.; Pasternak, R. F. J. Am. Chem. Soc. 2000, 122, 7494-7502. doi:10.1021/ja000738g

11. Mourtzis, N.; Paravatou, M.; Mavridis, I. M.; Roberts, M. L.; Yannakopoulou, K. Chem. - Eur. J. 2008, 14, 4188-4200. doi:10.1002/chem.200701650

12. Vizitiu, D.; Walkinshaw, C. S.; Gorin, B. I.; Thatcher, G. R. J. J. Org. Chem. 1997, 62, 8760-8766. doi:10.1021/jo9711549

13. Bunke, H.; Zerbe, O.; Schmid, H.; Burmeister, G.; Merkle, H. P.; Gander, B. J. Pharm. Sci. 2000, 89, 1335-1341.

14. Vallinayagam, R.; Bertschy, H.; Berger, Y.; Wenger, V.; Neier, R. Synthesis 2007, 3731-3735. doi:10.1055/s-2007-990825

15. Tamm, C. Pure Appl. Chem. 1992, 64, 1187-1191. doi:10.1351/pac199264081187

16. Gadelle, A.; Defaye, J. Angew. Chem., Int. Ed. Engl. 1991, 30, 78-80. doi:10.1002/anie.199100781

17. Vallinayagam, R.; Weber, J.; Neier, R. Org. Lett. 2008, 10, 4453-4455. doi:10.1021/ol801496j

18. van den Akker, J. T.; Iani, V.; Star, W. M.; Sterenborg, H. J.; Moan, J. Photochem. Photobiol. 2000, 72, 681-689.

19. Krijt, J. Peroxidizing Herbicides: Toxicology to Mammals and Non-target Organisms. In Peroxidizing Herbicides; Boger, P. Wakabayashi, K., Eds.; Springer: Berlin, Heidelberg, Germany, 1999; pp 384 ff. doi:10.1007/978-3-642-58633-0_15

20. Zidovetzki, R.; Levitan, I. Biochim. Biophys. Acta 2007, 1768, 1311-1324.

21. Theodossiou, T. A.; Yannakopoulou, K.; Aggelidou, C.; Hothersall, J. S. Photochem. Photobiol. 2012, 88, 1016-1022. doi:10.1111/j.1751-1097.2012.01144.x

\section{License and Terms}

This is an Open Access article under the terms of the Creative Commons Attribution License (http://creativecommons.org/licenses/by/2.0), which permits unrestricted use, distribution, and reproduction in any medium, provided the original work is properly cited.

The license is subject to the Beilstein Journal of Organic Chemistry terms and conditions:

(http://www.beilstein-journals.org/bjoc)

The definitive version of this article is the electronic one which can be found at: doi:10.3762/bjoc. 10.251 